\title{
RELATIONSHIP BETWEEN CORE STABILITY AND HAND FUNCTION RECOVERY PARAMETERS USING PHYSICAL THERAPY FOR PATIENTS AFTER STROKE
}

\author{
A. Juodžiukynaitè ${ }^{1}$, D. Suvaizdytè ${ }^{1}$, S.Stakauskienè ${ }^{1}, E$. Milinavičienè PhD². \\ ${ }^{1}$ Medical SPA “Eglès" sanatorija, 2Department of Rehabilitation, Lithuanian University of \\ Health Sciences.
}

\section{Introduction/ Background}

To evaluate core stability and hand function recovery parameters using different physical therapy methods for patients after stroke.

\section{Material and Methods}

44 patients after stroke were selected for this research. Patients were divided into two groups randomly, both groups consisted of 22 patients. The first group received traditional physical therapy exercises for hand function and core stability and the second group received physical therapy exercises using S-E-T conception for the same functions. The injury had to be in the middle cerebral artery, and in the left cerebral hemisphere, the patients' dominant hand had to be right, and patients had to be diagnosed with stroke for the first time. Hand movement repetition was measured by the reactiometer and hand motor function was evaluated using the motor activity test (Wolf), the Motor assessment scale (MAS) was used for the evaluation of combination movements in the upper extremity and the functional reach test was used to determine core stability.

\section{Results}

Physical therapy using S-E-T conception and traditional physical therapy improved reaction speed and reduced reaction unevenness of the affected hand for patients after stroke $(p<0,05)$. But physical therapy using S-E-T conception was more effective for the recovery of hand function (Figure 1). Physical therapy using S-E-T conception and traditional physical therapy improved core stability for patients after stroke $(p<0,05)$ (Figure $2)$. A relationship between core stability, hand function and reaction speed $(p<0,05)$ was established (Table 1$)$.

Figure 1. The distribution of subjects in groups by motor hand function before and after physical therapy

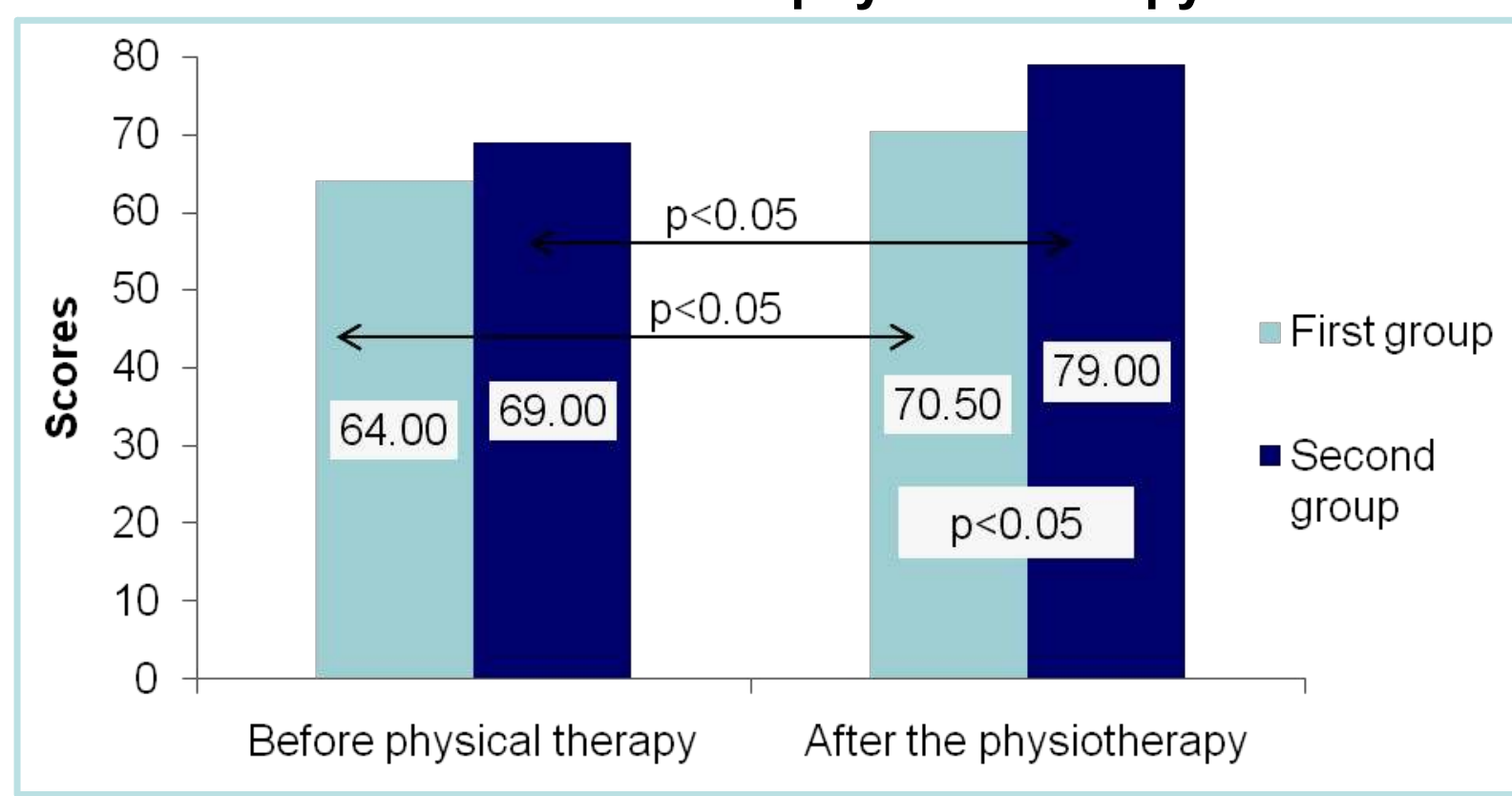

\section{Conclusion}

Physical therapy exercises for hand function and core stability using S-E-T conception and traditional physical therapy exercises for hand function and core stability are both effective in regaining lost function, reaction speed and strength of hand and core stability.

Table 1. The distribution of subjects in groups according to core stability, hand function and reaction speed

\begin{tabular}{|ccc|}
\hline Correlation & $\begin{array}{c}\text { Correlation } \\
\text { coefficient } r\end{array}$ & Value $-p$ \\
\hline $\begin{array}{c}\text { Core stability and hand } \\
\text { strenght }\end{array}$ & 0,376 & 0,012 \\
$\begin{array}{c}\text { Core stability and hand } \\
\text { reaction speed }\end{array}$ & $-0,244$ & 0,011 \\
\hline $\begin{array}{c}\text { Hand function and unevenness } \\
\text { of hand reaction speed }\end{array}$ & $-0,324$ & 0,032 \\
\hline
\end{tabular}

Figure 2. The distribution of subjects in groups according to core stability results before and after the physical therapy

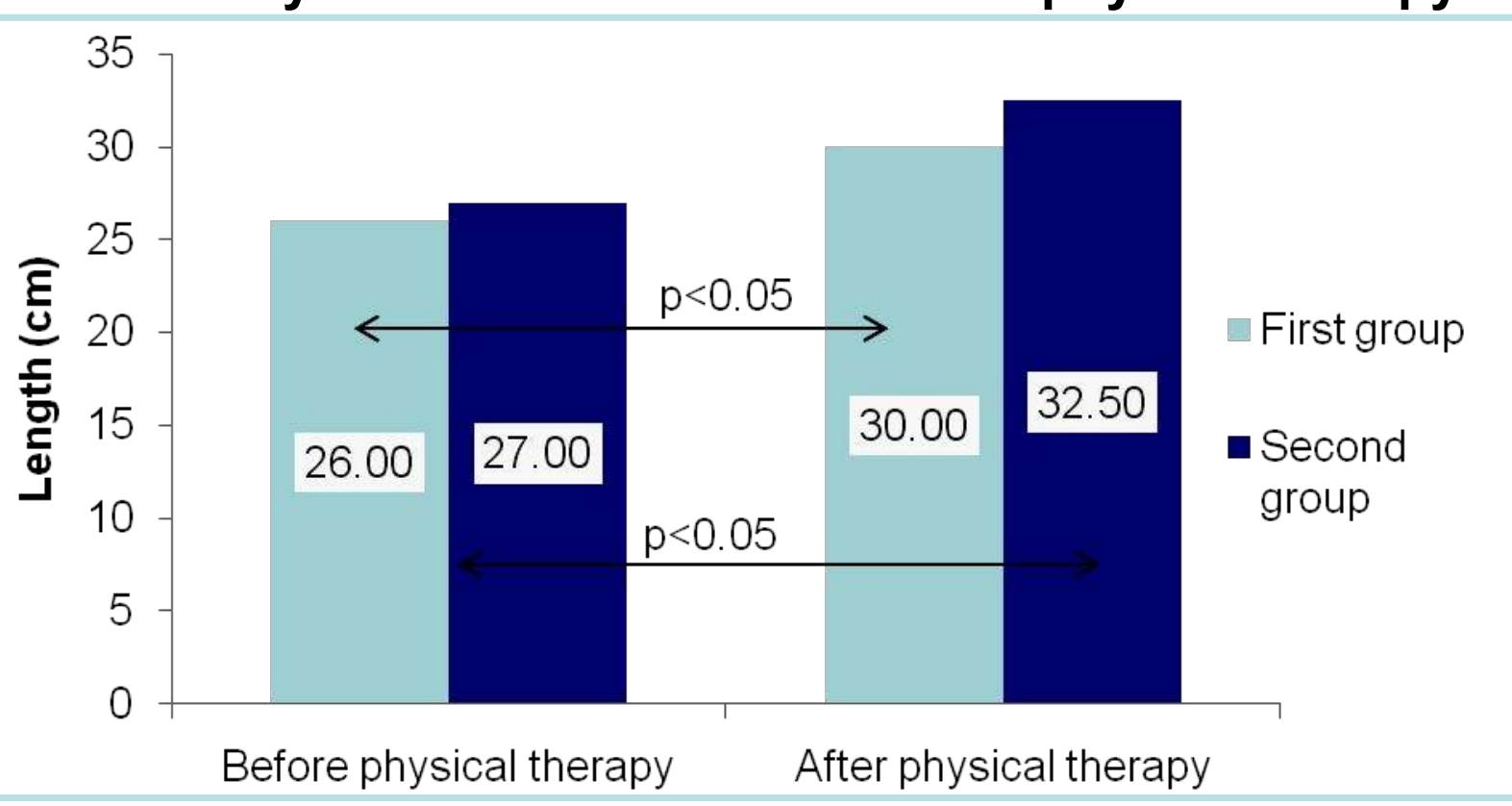

